\title{
Web and Social Media Presence in the Hospitality Industry: A Greek Island Case
}

\author{
Sotirios Karetsos \\ Informatics Laboratory, Department of Agricultural \\ Economics and Development, Agricultural University of \\ Athens, Greece \\ Email: Karetsos [AT] aua.gr
}

\author{
Maria Ntaliani \\ Informatics Laboratory, Department of Agricultural \\ Economics and Development, Agricultural University of \\ Athens, Greece \\ Email: ntaliani [AT] aua.gr
}

\begin{abstract}
The new opportunities offered by emerging technologies for better tourist services have affected the hospitality sector. Specifically, the use of the Web, in general, and the social media influence travelers' choices. Therefore, it is important for modern hotel businesses to be actively involved and present on the Web and social media. Moreover, COVID-19 outbreak has highlighted the importance for better choices that guarantee safety that must be made in advance. This study tries to investigate the use of the Web and social media by the hospitality sector in Greece using automated evaluation tools. The case study of the Rhodes island is selected as one of the most popular destinations in Greece for both internal and external tourists. Agritourism was also taken into account. Results show that the websites and Facebook are the most preferred tools for online presence, whereas there is low use of Instagram, LinkedIn and Twitter.
\end{abstract}

Keywords- Social Media, Website, Facebook, Hotels, Greece, Rhodes island, Agritourism

\section{INTRODUCTION}

Tourism and hospitality are among the world's largest industries. Globally, tourist arrivals increased from 528 million in 2005 to 1.19 billion in 2015 and 1.5 billion in 2019 . Hotels represent an important part of the tourism industry. Indeed, the value of global hotel industry in 2019 was 570 billion dollars. Overall, the economic contribution of tourism and hospitality to global GDP was 2.9 trillion U.S. dollars in 2019. Additionally, international tourist arrivals are forecasted to exceed 1.8 billion by 2030 [1]. Hospitality is an information demanding sector and the Internet has become a major information source for travelrelated decisions [2]. Usually, before going on a trip, travelers check information to plan and select between available options that include all trip phases. Indicatively, transportation plans include departure and arrival time schedules, connections with other transportation services and costs. Then, accommodation planning also requires much time. According to tourism type (e.g., adventure tourism, city tourism, ecotourism, agritourism, sports tourism), travelers check for hotels and other types of accommodation based on the costs and location (e.g., distance from city center or planned activities location, noiseless area), as well as the services offered during the stay (e.g., breakfast and meals, parking, bathroom, wi-fi). During their stay, travelers plan their daily visits, activities, places to eat and tour [3].
It is important that the greater the degree of risk in a prepurchase context, the greater the buyer tendency to seek information about the product. This need becomes more significant due to certain characteristics of the tourism product. Among these characteristics is, unlike factory-made products, the tourism product cannot be brought to the traveler; the traveler has to go to it. It would therefore be impossible for hotel companies to try to keep up with the data dictated by modern marketing and market demands. During the COVID-19 outbreak, information on safety measures and places that travelers are allowed to visit are required. Therefore, information before and during travelling is intensive and for many travelers represents a major emotional, time and money investment.

In the constantly evolving digital environment, the hospitality sector is trying to compete and adapt by rapidly adopting Web and social media technologies to target customers across the globe. Social media comprise virtual networks that allow travelers to interact with each other, develop communities, and share information, ideas, comments, ratings, and consequently influence traveling choices. Social network advertising spending worldwide in 2017 was around 60 , by the end of 2020 will have reached around 100 and it is forecasted to reach 135 billion U.S. dollars by 2025 [4]. Therefore, it is important for a modern business to actively participate and be present in social media. Hotels have recognized the importance of online marketing through the Web and social media. For example, luxury hotel chains invest significant resources to improve their online presence and have an active team that responds in a very short period of time to comments on social media.

In this context, the objective of this study is to investigate the use of the Web and social media by the hospitality sector in Greece through a case study of a globally famous destination, namely the Rhodes island. Hospitality sector represents a very significant sector for Greek economy with $20.8 \%$ contribution to GDP and $21.7 \%$ in employment. Every year, 31,348,377 of tourists visit Greece. Sunny weather in Greece prolongs tourism period, and allows tourism throw-out the year [5]. Tourists prefer Greece not only for its history and culture, but also natural landscapes and environmental diversity (e.g., rugged mountains, crystal-clear water beaches). Among the popular destinations are 
the exquisitely beautiful Greek islands. Therefore, Greece provides various types of tourism for different lifestyles, such as marine, agritourism. Regarding agritourism, it is an alternative type of tourism that is becoming more and more popular contributing to local development. In Greece, the development of such types of tourism was actively promoted (through the provision of economic incentives) in the country's less favored (rural) areas, facing the most severe structural problems while, in parallel, preserving rich cultural traditions, high value landscapes, and traditional occupations, which constitute the basis for alternative tourism development [6].

Despite the COVID-19 breakout, according to the influential Anholt-Ipsos Nation Brands Index (NBI) for 2020, Greece is a global leader in tourism since it is one of the top five countries with the strongest tourism brands [7]. However, the COVID-19 lockdown has severely impacted the hospitality sector. During the period January-September 2020 it recorded a revenue reduction of about $78.2 \%$ compared to the same period in 2019 [8]. In relation to its main tourism competitors (i.e., Spain, Italy, France and Portugal) Greece has the opportunity to improve its comparative position and recover faster. The large dispersion of its customers base gives Greece the opportunity to take advantage of various markets as they will recover [9]. In May 2020, Greek companies were surveyed on the effects of COVID19 lockdown and what they shall expect the next day. The survey involved 100 executives from Greek small and medium-sized enterprises with high growth rates in 2019, from 15 different industries. Digital transformation was indicated by one third of enterprises as the basis for a restart phase [10], showing an emergent need for transacting in the digital world. Social media can also contribute to this end.

The structure of the paper is as follows: the next section provides a literature review to depict the research interest in Web and social media presence of the hospitality sector at global level in general, and in Greece in particular. The third section presents the case study of the Rhodes island. A survey evaluating the websites and Facebook profiles that are used by Rhodes hotels using two automated tools is presented. Finally, the conclusions of the study and directions for future research are given.

\section{RESEARCH BACKGROUND}

In this section the current status of research on website and social media presence in the hospitality sector is investigated. A literature review was performed according to three steps [11]. Firstly, the research topic was specified. More specifically, in the context of this paper the review is trying to depict the research interest in Web and social media presence of the hospitality sector at global level in general, and in Greece in particular.

Secondly, the research databases where the literature review search would take place, as well as the specification of the search keywords were identified. Two well-known scientific databases, namely Scopus and Web of Science, were selected. The third step regarded the definition of the criteria used for searching the selected databases.
For the Scopus database, two keyword groups were used to check the research interest at global level. More specifically, the first group refers to the terms "website", "social media", "social networking", "social networks", "Facebook", "Instagram", "Twitter" and "LinkedIn" using the operator OR. The second group was consisted of two terms "hotels" and "hospitality" using again the operator OR. Between the terms of the first and the second group the operator 'AND' was used. This query resulted 1,410 journal articles in English that contain the abovementioned terms in their title, abstract, or keywords. The results were further filtered focusing on research published from 2015 to 2021 (early access or in press articles) and excluding scientific areas that were out of the scope of our research (e.g., arts and humanities, chemistry and chemical engineering, earth and planetary sciences, mathematics, nursery, veterinary). Therefore, the search resulted in 710 articles. The distribution of articles by year is: 6 in 2021, 160 in 2020, 164 in 2019, 112 in 2018, 100 in 2017, 98 in 2016, and 70 in 2015.

The five most popular subject areas are as follows (articles may fall in more than one subject areas): 573 in Business, Management and Accounting, 220 in Social Sciences, 163 in Computer Science, 52 in Engineering, and 43 in Economics, Econometrics and Finance. The ten most popular keywords were: social media (168), hotels (70), tourism (58), hotel industry (57), online reviews (45), hospitality (43), social networking (online) (38), sentiment analysis (36), marketing (30), and hospitality industry (28).

These results were further filtered with a third group of terms in order to specify the research interest for the case of Greece. The terms that were included (searched in title, abstract or keywords) are "Greece" or "Greek" using the operator AND to the previous two groups of terms. Scopus resulted four (4) documents, distributed as follows: one in 2020, two in 2019 and one in 2015. One article evaluates empirically whether the impact of social media analytics on customer satisfaction is contingent on the characteristics of different external stakeholders, including business partners (i.e., partner diversity), competitors (i.e., localized competition) and customers (i.e., customer engagement). Data were collected from 141 hotels operating in Greece [12]. The second article identifies crosscultural differences in service evaluations and specifically, in hotel appraisals among tourists from Central, Eastern (including Post-Soviet States), Northern and Southern Europe. 1,055 reviews for five hotels in Greece were used for the study [13]. The third article explores the attitudes of tourists toward digital marketing applications related to peer-to-peer short-term rental services within the sharing economy in the tourism sector [14]. Finally, the fourth article investigates the relation between social media use and employee creativity by adopting a knowledge management approach in order to consider the influence of social networks and interactions on individuals' creativity. Data were collected from Greek tourism professionals [15].

The third step was also applied for the Web of Science database. The first two groups of terms were searched in title, abstract or keywords of articles. The search returned 1,447 articles in English. After refining the search results including only articles published from 2015 to 2021 and excluding irrelevant Web of Science Categories, 836 documents were 
included in the search. The distribution of articles by publication year is: one in 2021, 178 in 2020, 214 in 2019, 137 in 2018, 111 in 2017, 109 in 2016, and 86 in 2015. The five most popular subject areas are as follows (articles may fall in more than one subject areas): 638 in social sciences (other topics), 349 in business economics, 34 in computer science, 34 in sociology, and 11 in communication. It must be noted that Web of Science database does not provide most popular keywords for a search.

When adding the third group of terms to focus on the case of Greece, the database returns six results, four of which were also returned in the Scopus database results. From the two additional articles, one is published in 2019 and one in 2015. The most recent article [16] studied the willingness to pay premium prices based on the perceptions of 328 holidaymakers leaving Athens. The other article [17] examined visitors' perceptions and relevant importance of social media when choosing a Mediterranean destination and also explored the importance of participating in an online community with shared characteristics among its members.

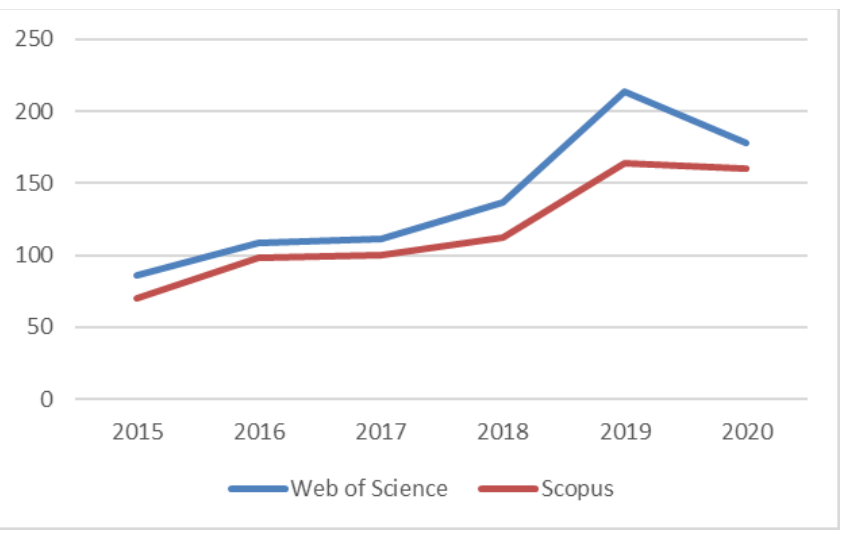

Figure 1. Article publication distribution by year

Figure 1 presents the publication distribution by year of the 710 and 836 articles returned from the search in the Scopus and Web of Science databases respectively. Globally, results show that there is an increasing research interest during the last five years for social media and the hospitality sector. Global research mainly focuses on the evaluation of online reviews from both customers' and hotels' sides, how social media are used for advertisement, how tourists are engaged and rate places and hotels they visit, and how social media users are converted into buyers. Regarding Greece, the results are rather poor, showing a very limited research interest; given that the tourism sector is among the top GDP contributors. In addition, none of the articles studies the adoption degree of web and social media by the hospitality sector.

\section{RHODES ISLAND Hotels' CASE STUDY}

Rhodes Island receives a significant part of domestic, as well as international tourists. More specifically, since 2016 more than 400.000 domestic and 2 million international tourists arrive by plane in the island [18]. In 2018, a research showed that tourists who choose Rhodes are married, up to 44 years old with higher education. In terms of financial status, the survey showed that $56.2 \%$ has an annual income of EUR 30,000 or more [19]. The main source of information for preparing their visit and stay in Rhodes island is the Internet (42.5\%) and travel agencies (34\%). $55.6 \%$ trusted an agent to plan their trip, but $42.3 \%$ only collected online information. The majority of visitors who choose the city of Rhodes major touristic places to stay, are more likely to stay for about a week. In addition, over $72 \%$ have visited the island again and the majority of them (72\%) are aged under 26. Finally, the main reasons for choosing the island are the natural environment, the seaside, the prolonged good weather and the quality of hotel service and the hospitality of the locals. Hotels in Rhodes Island in 2018 accounted to 489, namely 44 are one-star, 156 are two-star, 131 are three-star, 106 are four-star and 52 are five-star hotels. The majority of them use new technologies to advertise their services so as to attract more customers.

Since agritourism comprises a significant sector for Greece, was also studied for the case of Rhodes in order to be included in the study. Only one business was found to be advertised using the term agritourism. However, it does not offer typical agritourism services (i.e., visiting farm stands, picking fruit, or feeding animals staying at a farm, assisting in chores or agricultural / ranch work). In any case, the island is oriented to mass tourism and not to agritourism. This is consistent with the research of [20] who conclude that most of the agritourist holdings in islands operate in the margin of mass tourism with the same customers and the same product, without clear links to local agricultural production, local products, environment and cultural landscapes.

In the context of this study, firstly web and social media presence of hotels has been studied and; secondly, an evaluation of hotel websites and Facebook profiles have been evaluated using two automated tools. Specifically, for studying web and social media presence, hotels' websites and accounts in Instagram, LinkedIn, Facebook and Twitter have been studied according to star categories. Special focus has been given on Facebook since it is the most popular social media for business' online promotion in Greece [21]. Globally, there is a wide variety of classification schemes used by different organizations for providing an indicator on hotel standards. The most popular is the star system, using from one to five stars to express quality from small and usually family-owned business to large and luxurious hotels.

There are various tools for the assessment of websites (e.g., Nibbler, WooRank, Clarity Grader) and Facebook profiles (e.g., Facebook Analytics, Simply Measured, Whatagraph). In this study the evaluation of hotels' websites and Facebook profiles the Website grader (website.grader.com) and LikeAlyzer (www.crunchbase.com/organization/likealyzer) tools have been used respectively. The selection of these tools has been based on the fact that they are Web-based and free to use, and have been used in other scientific studies by researchers. 


\section{A. Web and Social Media Presence}

In general, regarding their online presence 41 hotels use only a website; 27 use only social media; and 299 use a website and social media. All hotels that use social media use Facebook. Totally, out of 489 hotels 340 have websites. The number of hotels having a website for each star category is as follows: 14 (one-star), 90 (two-star), 90 (three-star), 99 (four-star), and 47 (five-star). Usually, the websites contain information and pictures about their facilities and services, customer reviews and links with their social media. More advanced websites make use of multimedia to present accommodation more attractive and interesting. Generally, one-star hotel websites provide only basic information and insufficient content through a home page and a couple of simple pages with communication details. On the other hand, five-star hotels usually present rich content allowing interaction with their clients.

Regarding social media usage, Facebook is the most popular, with 326 hotels (67\%) using Facebook, 110 (22\%) Twitter, 69 (14\%) Instagram, and 29 (6\%) LinkedIn. From all hotels, 2\% uses all four of the aforementioned social media, $8 \%$ uses three social media, $19 \%$ uses two, $38 \%$ uses only one, and $33 \%$ does not use any social media at all.

The number of hotels having a Facebook profile for each star category is as follows: 10 (one-star), 84 (two-star), 92 (threestar), 95 (four-star), and 45 (five-star). Instagram, a social media that is quite popular among young people, presents low adoption by hotels. One- to three-star hotels show very low usage of Instagram. Facts are worse for LinkedIn usage for all star categories. In general, social media are used to present and advertise services and offers, whereas specifically Facebook seems to open a modern channel of communication with customers at minimum cost and, additionally, it offers a widget that allows booking services directly from Facebook profile. Web and social media presence of Rhodes hotels according to star category is presented in Table 1.

TABLE I. Web AND Social Media Presence by Star CATEgory

\begin{tabular}{|l|c|c|c|c|c|}
\hline & $\begin{array}{c}\text { Website } \\
(\boldsymbol{\%})\end{array}$ & $\begin{array}{c}\text { Facebook } \\
(\boldsymbol{\%})\end{array}$ & $\begin{array}{c}\text { Instagram } \\
(\boldsymbol{\%})\end{array}$ & $\begin{array}{c}\text { LinkedIn } \\
(\boldsymbol{\%})\end{array}$ & $\begin{array}{c}\text { Twitter } \\
(\boldsymbol{\%})\end{array}$ \\
\hline One-star & 32 & 23 & 7 & 2 & 5 \\
\hline Two-star & 58 & 54 & 4 & 3 & 14 \\
\hline Three-star & 69 & 70 & 5 & 3 & 21 \\
\hline Four-star & 93 & 90 & 30 & 9 & 32 \\
\hline Five-star & 90 & 87 & 40 & 17 & 48 \\
\hline Total & $\mathbf{7 0}$ & $\mathbf{6 7}$ & $\mathbf{1 4}$ & $\mathbf{6}$ & $\mathbf{2 2}$ \\
\hline
\end{tabular}
maintain a website. However, Website Grader could not provide results for 15 of them. This is due to low website quality and/or the fact that the page has not been optimized in accordance with the new applicable online management data. Table 2 presents the average values of each of the aforementioned features for 325 hotels, according to star category. Regarding the performance feature, one-star hotels score the highest. This could be explained by the fact that one-star hotel websites are based on simple technologies and offer basic information that is downloaded very fast, thus are more responsive to the visitor. The more content offered on a website the more time is needed to be loaded on the web browser. Concerning the mobile feature,

The websites of the selected hotels have been analyzed the Website Grader tool. This tool has been used to analyze the as well as the whole set, shows if a website works efficiently and possible upgrading initiatives that could improve the overall

- Performance: This feature assesses the overall appearance of the page, its size and the speed of response to the visitor. It is perhaps the most important the visitor. It can contribute to the traffic and appeal of the business. Values range from 0 to 30 and is calculated based on seven characteristics namely: page size, page compression and, render blocking.
comests, page speed, browser cachil

- Mobile: This feature is about the ability to view the page on mobile devices and especially on smartphones. As a large proportion of the public visits all pages and makes their mobile phones, the flexibility of a page to operate efficiently on these devices is important. The value ranges from 0 to 30 and is calculated based on two characteristics namely: responsive and, viewport.

- SEO: Checks if the website is easy for users to discover, and easy for search bots to understand, with better page titles, headings, and meta descriptions. To achieve a good score the website shall: (a) have page titles with no keywords, (b) have meta descriptions with no longer than 300 characters in length and should be relevant to the page, (c) have heading tags that distinguish headings from core page content, and (d) offer site maps that help
users navigate quickly and easily. Values range from 0 to 30 .

- Security: This feature checks the level of security against the threats and attacks of the Internet. The availability of SSL certificates is checked so that to verify that the website is authentic and trustworthy. Values range from 0 to 10 .

Website analysis has been performed for all 340 hotels that 
regardless of their stars, hotels present average level scores, showing there is room for improvement of the mobile side of their websites. SEO scores are low for the majority of the hotels, with exception five-star hotels. This affects hotel discovery by clients-particularly for one-star hotels-and requires better description of websites for search engines. Commenting on security, is acceptable for all categories, with five-star hotels approaching 9/10. In general, hotels with more stars have a better total score. There is a small divergence between two- and three-star hotels, which however is not that significant (i.e., $0.77 \%$ ). Table 2 and figure 2 below summarize the analysis results.

TABLE II. WEBSITE EVALUATION CHARACTERISTICS By STAR CATEGORY

\begin{tabular}{|c|c|c|c|c|c|}
\hline & $\begin{array}{c}\text { one- } \\
\text { star }\end{array}$ & $\begin{array}{c}\text { two- } \\
\text { star }\end{array}$ & $\begin{array}{c}\text { three- } \\
\text { star }\end{array}$ & $\begin{array}{c}\text { four- } \\
\text { star }\end{array}$ & $\begin{array}{c}\text { five- } \\
\text { star }\end{array}$ \\
\hline $\begin{array}{c}\text { Performance } \\
(\text { max 30) }\end{array}$ & 21.16 & 19.94 & 20.31 & 19.61 & 19.71 \\
\hline $\begin{array}{c}\text { Mobile } \\
(\text { max 30) }\end{array}$ & 20.53 & 23.14 & 22.85 & 23.47 & 22.85 \\
\hline $\begin{array}{c}\text { SEO } \\
(\text { max 30) }\end{array}$ & 14.84 & 19.04 & 18.31 & 19.65 & 23.05 \\
\hline $\begin{array}{c}\text { Security } \\
(\text { max 10) }\end{array}$ & 7.37 & 6.28 & 6.16 & 6.82 & 8.78 \\
\hline $\begin{array}{c}\text { Total } \\
\text { (max 100) }\end{array}$ & $\mathbf{6 3 . 9 0}$ & $\mathbf{6 8 . 4 0}$ & $\mathbf{6 7 . 6 3}$ & $\mathbf{6 9 . 5 5}$ & $\mathbf{7 4 . 3 9}$ \\
\hline
\end{tabular}
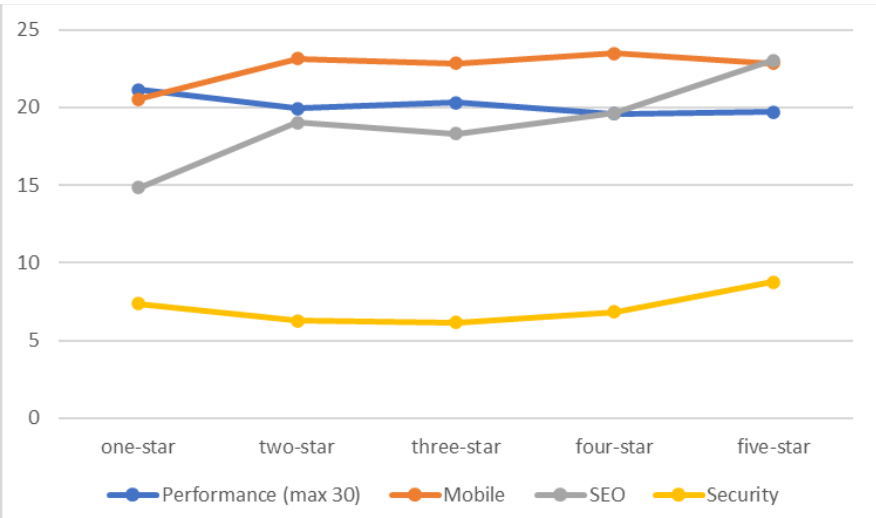

Figure 2. Hotels' evaluation with Website Grader

\section{Facebook Evaluation}

The Facebook profiles of the hotels have been evaluated by the LikeAlyzer analytics application. This tool was available online for free until November 2019, enabling the assessment of Facebook presence and impact through the following four parameters [12]:

- Frontpage: refers to the visitor's first impression of the page. This includes information about the business, for example, about, username, profile picture and cover photo, and call to action.
- About: regards more detailed business information, such as milestones, contact information, location and products.

- Activity: concerns the activity of the page and how often it occurs. It evaluates the number of pages liked, native Facebook videos, the number of posts per day, and the average post length.

- Response: refers to the response to visitors, either through comments on posts or through personal messages. It evaluates whether visitors can post.

- Engagement: evaluates visitors' activity on the page, and some features that can only be accessed by the page developer. The number of people who have interacted with the page and the total page likes are measured.

It has to be noted that LikeAlyzer does not provide an overall score, but each feature is graded from 0 to $100 \%$. Table 3 and figure 3 present the average values of each of the aforementioned parameters for 326 hotels, according to star category. Concerning the Frontpage and About parameters, all hotels present high scores, with five-star hotels being on the top. Therefore, hotels are very interested not only in visitors' first impression but also care to include more detailed information on their business. The Activity parameter is characterized by very low scores, showing some sort of negligence of content sharing on a regular basis. Two-star hotels present the poorest score. Activity parameter scores comprise a paradox, since efficient social media usage requires regular engagement with the user. Regarding the Response parameter, in general the scores are high and above $80 \%$, with three-star and four-star hotels in the lead. Finally, the Engagement scores are much beyond expectation, showing that hotels should improve their interactivity with their clients.

TABle III. FACEBook EVAluation Parameters by Star Category

\begin{tabular}{|c|c|c|c|c|c|}
\hline & one-star & two-star & three-star & four-star & five-star \\
\hline $\begin{array}{c}\text { Frontpage } \\
(\%)\end{array}$ & 85.88 & 85.65 & 87.98 & 92.88 & 96.25 \\
\hline $\begin{array}{c}\text { About } \\
(\%)\end{array}$ & 85.00 & 82.73 & 82.97 & 85.87 & 87.34 \\
\hline $\begin{array}{c}\text { Activity } \\
(\%)\end{array}$ & 22.38 & 12.04 & 20.84 & 23.46 & 36.45 \\
\hline $\begin{array}{c}\text { Response } \\
(\%)\end{array}$ & 87.50 & 88.06 & 94.90 & 90.24 & 82.57 \\
\hline $\begin{array}{c}\text { Engagement } \\
(\%)\end{array}$ & $\mathbf{0}$ & $\mathbf{0}$ & $\mathbf{0}$ & $\mathbf{0 . 9 5}$ & $\mathbf{3 . 0 7}$ \\
\hline
\end{tabular}




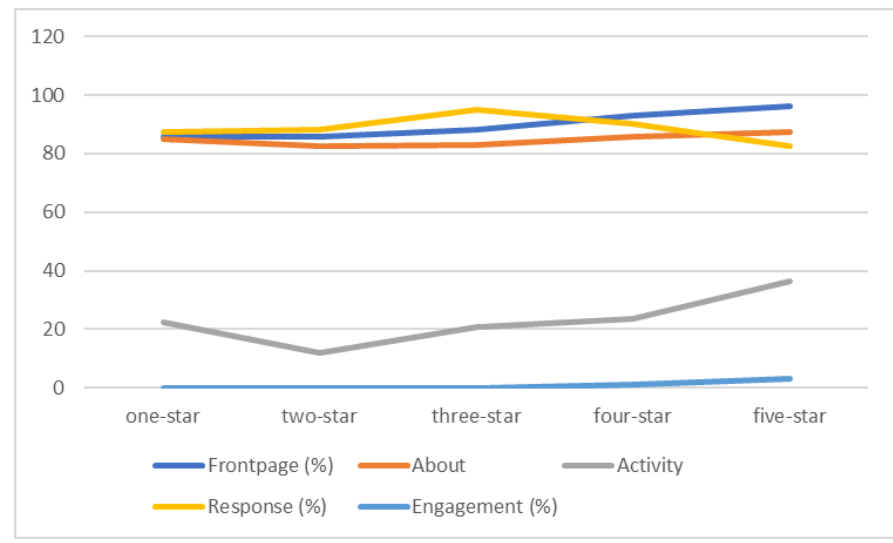

Figure 3. Hotels' Facebook profiles evaluation with LikeAlyzer

\section{CONCLUSIONS}

During the COVID-19 breakout the hospitality sector in Greece marked significant revenue loses and during its restart will have to respond to more demanding clients who will seek information online. Since travelers cannot pre-test the product or easily get their money back if the trip does not meet up to their expectations, access to accurate, reliable, timely and relevant information is essential to help them make an appropriate choice. This work studied the website and social media presence of 489 hotels in Rhodes, in order to provide insights on increasing their adoption and providing quality information.

The results show the website and Facebook are the most preferred tools for online promotion by all hotel star categories, since $61 \%$ use both of them. However, only four- and five-star hotels present satisfactory use of websites and Facebook. Interestingly, all hotels that use social media use Facebook; whereas the use of Instagram, LinkedIn and Twitter is low. Hotels' websites and Facebook profiles were assessed with automated tools, which evaluate technology aspects of them. In general, hotels are characterized by unsatisfactory scores. Particularly for Facebook, hotels present some sort of negligence of content sharing on a regular basis. This fact shows that hotels do not take advantage of the main opportunity offered by social media that is the regular engagement with the user. It has to be noted that LikeAlyzer analysis provides average values for specific parameters and does not provide an explanation why actually these parameters differ between star categories. This comprises a limitation of the study, since no relevant bibliography can provide evidence on interpreting the results in depth, such as why three-star hotels have a better Response value than five-star hotels. This lack of research is possibly due to the restriction measures of COVID-19 outbreak, as it requires interviewing hotel stakeholders, who are currently struggling during a period that their economic sustainability is at stake.

However, there is still room for improvement, and even more for smaller businesses and different types of tourism. In specific, agritourism businesses can benefit from the use of Web and social media even in popular islands like Rhodes. In [22 and 23] it is mentioned that that the role of social media appears to be effective in developing a customer base and connecting it with other likeminded travelers, creating a community where agritourism or rural tourism businesses can spread focused information about promotions and events. Therefore, future work will include the assessment of social media usage by agritourism hotels in Greece and compare with other Mediterranean countries. Also, research for depicting hotels' point of view regarding social media usage has to be undertaken for highlighting obstacles and drivers for their adoption.

This study has focused on the web and Facebook presence of individual hotels. However, the hotel sector, as well as travelers' culture are rapidly changing through innovative online platforms, such as Booking.com and Airbnb, and mobile applications. On one hand, these online platforms facilitate travelers in choosing their accommodation among hotels, apartments, and even houses, and by providing marketing, booking and payment mediation processes for them. According to literature, there is no research on the effects of these platforms on the hotel's income focusing on the case of Rhodes island. On the other hand, further research is required for evincing the capabilities of mobile apps, like WhatsApp and Viber, in supporting hotels' social media presence.

\section{REFERENCES}

[1] Statista, "Global tourism industry - statistics \& facts", https://www.statista.com/topics/962/global-tourism/, 2020, (Accessed 04-12-2020).

[2] I.C.C. Chan, J. Ma, R. Law, D. Buhalis, R. Hatter, "Dynamics of hotel website browsing activity: the power of informatics and data analytics", Industrial Management \& Data Systems, Vol. 121, 2020.

[3] A. Dickinger, and L. Lalicic, "Tourist-driven innovations in social media: an opportunity for tourism orga

[4] nisations", Advances in social media for travel, tourism and hospitality: New perspectives, practice and cases. Routledge Editions, 2017.

[5] Statista, "Social Media Advertising", https://www.statista.com /outlook/220/100/social-media-advertising/worldwide, 2020, (Accessed 04-12-2020).

[6] INSETE - Institute of Greek Tourism Confederation, "Main Greek Tourism Figures", https://sete.gr/el/stratigiki-gia-ton-tourismo/vasikamegethi-tou-ellinikoy-tourismoy/, 2019, (Accessed 13-11-2020).

[7] A. Koutsouris, I. Gidarakou, F. Grava, A. Michailidis, "The phantom of (agri)tourism and agriculture symbiosis? A Greek case study", Tourism Management Perspectives, Vol. 12, pp. 94-103, 2014.

[8] Ipsos, "Anholt-Ipsos Nation Brands Index (NBI)", press release, https://www.ipsos.com/sites/default/files/ct/news/documents/202010/nation-brand-index-2020-pr.pdf, 2020, (Accessed 28-12-2020)

[9] INSETE - Institute of Greek Tourism Confederation, "Statistics Bulletin - November 2020", No65, https://insete.gr/wpcontent/uploads/2020/11/Bulletin_2011-1.pdf, 2020, (Accessed 07-122020)

[10] INSETE - Institute of Greek Tourism Confederation, "The COVID-19 Pandemic and the Greek Tourism", https://insete.gr/wpcontent/uploads/2020/04/2004_COVID-19_Greek_Tourism.pdf, 2020, (Accessed 04-12-2020)

[11] SEPE - Federation of Hellenic Information Technology and Communications Enterprises (2020), "Digital Transformation: the

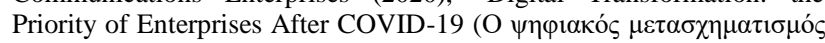

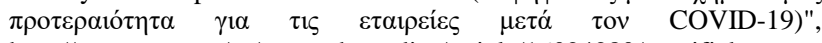
http://www.sepe.gr/gr/research-studies/article/16024280/o-psifiakos- 
metashimatismos-proteraiotita-gia-tis-etaireies-meta-ton-covid-19-/, 2020, (Accessed 16-10-2020).

[12] C. Costopoulou, S. Karetsos, and M. Ntaliani, "Investigating Educational Mobile Apps for Agriculture", International Journal of Sustainable Agricultural Management and Informatics, Vol. 6, No. 3, pp. 272-287 2020.

[13] Y. Wang, M. Zhang, Y.K. Tse, and H.K. Chan, "Unpacking the impact of social media analytics on customer satisfaction: do external stakeholder characteristics matter?", International Journal of Operations \& Production Management, Vol. 40 No. 5, pp. 647-669, 2020.

[14] R.H. Tsiotsou, "Rate my firm: cultural differences in service evaluations", Journal of Services Marketing, Vol. 33 No. 7, pp. 815-836, 2019.

[15] L. Tsourgiannis, and S. Valsamidis, "Digital marketing in tourism: why Greek tourists use digital marketing applications like Airbnb", International Journal of Culture, Tourism and Hospitality Research, Vol. 13 No. 4, pp. 473-486, 2019.

[16] M. Sigala, and K. Chalkiti, "Knowledge management, social media and employee creativity", International Journal of Hospitality Management, Vol. 45, pp. 44-58, 2015.

[17] M. Fragkogianni, "Willingness to pay premium prices in accommodation establishments", Hospitality and Society, Vol. 9 No 3, pp. 349-374, 2019.

[18] A. Kavoura, and A. Stavrianeas, "The importance of social media on holiday visitors' choices - the case of Athens, Greece", EuroMed Journal of Business, Vol. 10 No. 3, pp. 360-374, 2015

[19] Statista, "Number of international air arrivals to selected Greek islands in the South Aegean region of Greece from 2010 to 2019", https://www.statista.com/statistics/880532/south-aegean-greek-islandsinternational-air-arrivals/, 2020, (Accessed 21-11-2020).

[20] INEMY-Institute of Commerce and Services, "Commerce and Tourism in Rhodes", https://inemy.gr/wp-content/uploads/2018/01/rodos.pdf, 2018, (Accessed 05-10-2020).

[21] S. Karampela, T. Kizos, and I. Spilanis, "Evaluating the impact of agritourism on local development in small islands", Island Studies Journal, Vol. 11, No. 1, 2016, pp. 161-176, 2016.

[22] Statista, "Leading social media platforms used by marketers worldwide as of January 2020", https://www.statista.com/statistics/259379/socialmedia-platforms-used-by-marketers-worldwide/, 2020, (Accessed 15-122020).

[23] M. Phillips, D. T. McFaddenand, M. Sullins, "Possible Roles for Social Networking in Agritourism Development". Agricultural Marketing Report, No 1, pp 1-9, 2010.

[24] Y. Joo, H. Seok, Y. Nam, "The Moderating Effect of Social Media Use on Sustainable Rural Tourism: A Theory of Planned Behavior Model", Sustainability, 2020, 12(10). 